\title{
Chapter 8 \\ Trajectory Types Across Network Positions: Jazz Evolution from 1930 to 1969
}

\author{
Charles Kirschbaum
}

The study of organizational fields has been prevalent throughout organizational studies, strategic management, economic sociology and economic geography. The field construct has emerged as a powerful analytical concept that affords a holistic view of a social system. In this chapter, I espouse the idea that a field is a social space that encloses the main aspects of certain actors' institutional lives, and where the field's actors interact with each other in a more intensive way compared to their interactions with outside actors (DiMaggio \& Powell, 1983). Specifically, the jazz field includes musicians, critics, schools, magazines, and so on. Its formal and informal institutions include, inter alia, how music is constructed and interpreted, as well as the main practices in recruiting musicians for recording sessions. Its interactions include, inter alia, relational events such as playing together in jam sessions or in studios.

Throughout this chapter, my concern is to contribute to the literature of field dynamics. In particular, I explore the transition from a normative to a competitive configuration (Anand \& Peterson, 2000). In a normative field, social action is usually driven by rule-following, with these norms being enacted by central and dominant players. In competitive fields, by contrast, central actors dominate other actors, too, but norm-following does not rely on rule enforcement. Softer power, such as influence, becomes much more prevalent in competitive fields.

To be sure, both these field ideal types evoke the core-and-periphery framework, as though such a structure could be taken for granted. However, a closer inspection of the concrete historical process that leads from one ideal type to another can shed light on whether such a structure remains the same and indicate the extent to which topological changes during the process constitute main events and turning points. This examination may reveal that a core-periphery structure looks very similar in

\footnotetext{
C. Kirschbaum $(\bowtie)$

Insper Instituto de Ensino e Pesquisa,

Rua Quatá 300, Vila Olímpia 04546042, São Paulo, Brazil

e-mail: charlesk1@insper.edu.br
} 
both ideal types, although the core is fragmented and rearranged in the course of the process.

Although this macro-topological investigation is itself important to understanding field dynamics, I claim in this chapter that it is necessary to add the actor's trajectory into the analysis. If a field migrates from a normative logic toward a competitive one, what happens to the members of the incumbent elite? Assuming that they are able to sustain their dominant position through coercion or by hoarding key resources in the field, what is their fate as the field migrates to a competitive logic? Are they displaced and expelled? Or are they able to reconnect?

The goal of this paper is to address these lines of inquiry by using of the coevolutionary and network perspectives, taking as an example the evolution of jazz musicians' trajectories from 1930 to 1969 . I begin by exploring the structural changes in the jazz field during those almost four decades. I have also obtained a blockmodeling image of musicians' networks throughout this period in order to understand how musicians associated with different trajectories were positioned vis-à-vis each other. The jazz case provides a rich context for understanding the shift between types of field configurations given the transformations it experienced during these decades and the correspondent impact on musicians' trajectories (Kirschbaum, 2007). Furthermore, the geographic location of recording sessions became less centralized in New York (specifically) and the United States (in general). Results shown later in the chapter suggest that competitive fields present a lower distinction between core and periphery than do normative fields. Increasing centrifugal forces causes a paradigm crisis. As a result, although a new elite emerges and become central, members of the former elite eventually play the role of brokers when younger musicians become distant from each other.

\section{Normative and Competitive Field Structures}

Anand and Peterson (2000) and Peterson and Anand (2002) identify two kinds of organizational fields: normative and competitive. ${ }^{1}$ Within normative fields, individuals are driven mainly by norms established by dominant authoritative actors. Central players dominate peripheral actors by controlling the field's main resources and schemata. ${ }^{2}$ It is unsurprising, therefore, that innovations are usually introduced top-down, relatively buffered from competitive pressures. Along these lines, a classical example of a normative field is described by DiMaggio's (1991) research on U.S. art museums that shows central players sanctioning the field's norms.

\footnotetext{
${ }^{1}$ Fields are defined as "a community of organizations that partakes a common meaning system and whose participants interact more frequently and fatefully with one another than with actors outside the field" (Scott, 1995, p. 56).

${ }^{2} \mathrm{~A}$ schema is defined as "the set of shared assumptions, values, and frames of reference that give meaning to everyday activities and guide how organization members think and act" (Rerup \& Feldman, 2011, p. 578).
} 
In contrast, individuals in competitive fields are less constrained by normative rules and driven more by competitive forces. In contrast to action driven by normative rules established by authority, action impelled by competitive forces registers a balance between innovation and imitation (Anand \& Peterson, 2000). Leblebici, Salancik, Copay, \& King (1991) provide the example of the transformation of the radio broadcasting industry in the United States, showing that most innovations were introduced by peripheral actors.

Both these ideal-type depictions of a field evoke a core-periphery network topology. But while innovations within normative fields are first adopted at their core, in competitive fields they are initially created and adopted on the periphery. Nevertheless, in both depictions it is assumed that the overall core-periphery structure remains the same, or that changes are too subtle to be accounted for. Undoubtedly it is possible to envisage distinct mechanisms in play that help generate equivalent core-periphery structures. Within normative fields, dominant actors are assumed to use their power to remain at the core of the field. Conversely, new musicians entering the field are attracted to established players, a process that creates an asymmetric structure (Barabási, 2003). Because individuals prefer to connect to prominent actors who control key resources, peripheral actors will connect more frequently to core actors than with each other. As a result, a core-periphery structure emerges in which the field is dominated by a cohesive core that is surrounded by a fragmented periphery.

Alternative mechanisms may also work to generate an equivalent core-periphery structure in competitive fields. Although core actors cannot simply coerce peripheral actors to follow standards and rules, they may be able to exert influence. This occurs because central actors have better access to information (Lena \& Pachucki, 2013). Furthermore, peripheral actors may still attempt to connect to core actors in order to associate with high-status musicians (Podolny, 2001).

In spite of this apparently similar outcome in competitive and normative fields, it can be asked whether the asymmetry between core and periphery is actually the same. While most resources in normative fields are controlled by core actors, in competitive fields resources are more freely allocated among musicians. To illustrate this distinction, it is useful to look at a recording session in these different settings. In the normative phase of the jazz field, bandleaders are usually hired by recording companies under long-term contracts. This situation gives bandleaders considerable powers of discretion to employ sidemen of their choosing for the planned recording sessions. In the competitive phase of the jazz field, by contrast, musicians do not have long-term contracts with recording companies (Perrow, 1986). Although the latter approach represents an instability factor, it also encourages a musician to constitute a band by inviting sidemen to play together, with lower production costs making it possible for them to record samples to send to recording companies. The combination of the centripetal tendency (new musicians continuing to look to play with core actors) with the centrifugal force (cheap production and distribution costs enabling higher levels of entrepreneurship activity) can result in a core-periphery structure in which peripheral actors may present higher cohesion among themselves than is seen in a normative configuration's structure. This 
discussion leads me to investigate the following aspects underlying normative and competitive fields: Is there a core-periphery structure within both normative and competitive fields? Are these structures distinct from each other? What can be learned from the process of transition from one configuration to another?

So far I have explored the macro-topological structure of competitive and normative fields. In the next section, I explore the musicians' trajectories as an analytical dimension additional to the topological.

\section{Networked Trajectories}

Most analyses of field structure rely on topological descriptions. In each crosssectional analysis (or temporal slice), individuals are aggregated into positions. Rarely is an individual's history in the field preserved. The best way to illustrate this problem is by evoking a Markovian world. In a Markov chain approach, social systems are modeled as if trajectory were meaningless. Hence, if individuals are allocated to a position (whether core or periphery) at a given point in time, it does not matter where they were before that point. While this kind of approach simplifies the analysis, it generates several problems. First, it assumes that those individuals have no memory, and that their past experience is entirely subsumed in their present location. Second, from a relational point-of-view, it assumes that other individuals will be indifferent to one's trajectory, without any consideration of reputation, pedigree, and other biographical factors. ${ }^{3}$

In contrast, the existing literature has shown that trajectory is an important construct because it reveals how similar outcomes are attained through different processes among, for instance, firms (Stark \& Vedres, 2006), poets (Dubois \& François, 2013), or painters (Accominotti, 2009). Moreover, I argue that individual trajectories do indeed matter and that these are best understood as embedded in the field's historical evolution (Bourdieu, 1993; Giuffre, 1999).

In order to illustrate this idea, I take the example of a normative field, which is typically characterized by stable stylistic rules enacted by dominant players. One possible career track is the elite trajectory, represented by individuals who attain centrality in the field and who remain in central positions for a long period of time. On the other hand, there may be individuals who stay on the periphery but are able to survive in the field for a long time as well. Finally, some musicians might stay in the field only for a short time, limited to the periphery. One important line of inquiry is studying how dominant players interact with individuals from other trajectories. Do elite trajectory individuals relate only among themselves? If wanna-be trajectory musicians (short-lived and peripheral) attempt to break into the field, in what circumstances are they able to play with elite musicians? In normative fields, one

\footnotetext{
${ }^{3}$ A third point could be added to this list: The sequence of events does not matter (Abbott, 2001). I do not explore this third point in this chapter because it would require an approach similar to sequence analysis.
} 
can envisage a social system in which tiers of players relate to each other. Dominant musicians (with a high centrality and a long period in the field) recruit musicians from a surrounding tier (mid-periphery players, with long periods in the field). The latter, in turn, recruit players, but having fewer opportunities than dominant players, they are only able to secure shorter-duration performance gigs for their recruits. As a result, some of these more peripheral sidemen will have to leave the field to earn an adequate income from other sources.

By contrast, when a field migrates from a normative to a competitive configuration, new elites challenge previous ones in order to establish new paradigms. From this perspective, artists who start their trajectory as avant-garde challengers to the established artistic idiom strive for recognition among peers and critics. If this recognition is granted, these individuals are likely to attain a dominant position in the field (Bourdieu, 1993, 1996). What effect does this type of disruption have on the fate of individual trajectories? Taking trajectory as a key analytical concept again, how do individuals with different trajectories relate to each other?

If all that is being observed is a turning point, whereby one paradigm is displaced by another (i.e., the field remains normative and only a change of stylistic paradigm occurs), then it could be suggested that an established elite is replaced by a new one. Concretely speaking, the new elite would have strong presence at the field's core and also demonstrate a long period in the field, like the previous elite. Nonetheless, distinct apex moments may be found from one generation to the next.

However, when a field migrates from a normative to a competitive configuration, dominant actors are less able to maintain hegemony, and new elites displace existing ones over shorter temporal cycles. As a consequence, musicians with a history of presence at the field's core may also present shorter permanence in the dominant position. But what happens to the "fallen" elite? Do they become obsolete, as though musicians were similar to technologically outdated pieces of machinery? Are they able to reconnect with other musicians outside of the new elite? Displaced musicians might be compelled to play with peripheral musicians. If so, it should be possible to observe a higher level of social intercourse between musicians from different trajectories in competitive fields. This discussion leads me to ask how competitive fields impact the length of musicians' occupation of dominant positions.

The main goal of this preliminary discussion is to identify the initial challenges to understanding the evolution of a field vis-à-vis its embedded trajectories, while evoking a set of basic building blocks in order to construct its narrative.

\section{Data Collection}

\section{Source of Relational Data}

Musicians establish various types of relationships, from friendships to romantic affairs, in contexts ranging from joint session recordings to non-recorded jam sessions. Innovations can, of course, emerge as a result of all of these interactions. Nonetheless, 
I focus on one specific kind of relationship: joint session recordings. In joint session recordings, musicians are in their closest contact with the commercial side of the jazz art world, and their final product success has a direct impact on their trajectories. To gather the album data, I consulted the Crazy Jazz website. Crazy Jazz is a compact disk (CD) seller specializing in jazz titles. The universe of music albums at Crazy Jazz comprises 5572 LPs (long play albums records) produced between 1930 and 1969. ${ }^{4}$

The ideal would be to consider only those titles that reflect original recording sessions as relational data. However, many of the titles available are collections and compilations that could interfere with an accurate interpretation. Collection titles could establish relationships that did not exist (e.g., the compilation All Star Swing Players could wrongly link Benny Goodman to Duke Ellington). On the other hand, compilations may cover a lengthy period of the artist's production and include changes of style, making it difficult to identify when relationships with other players were established, and when the artist in question developed a certain style (e.g., Dizzy Gillespie's biography could mistakenly relate swing to Afro-Cuban jazz).

In order to minimize these effects, I eliminated collection albums from the database. Nonetheless, I could not simply eliminate compilation albums, because several titles were originally released individually as singles and later reissued on compilation CDs. As a solution, I limited compilations to a maximum 5-year range, taking the release year as the initial year of the period covered. ${ }^{5}$

\section{Preparation of the Network}

From the information taken from the LPs and their featured artists, I built three preliminary databases: a list of musicians, a list of LPs, and a list of relationships between LPs and musicians.

The LP database was divided into 85-year periods: 1930-1934, 1935-1939, 1940-1944, 1945-1949, 1950-1954, 1955-1959, 1960-1964, and 1965-1969. For each period, I counted the number of titles recorded by all pairs of musicians. In order to build the database of ties, I considered only those pairs that had at least two titles recorded in common. Next, I dichotomized all relationships without considering the strength of the tie. Table 8.1 shows descriptive statistics for each period's network.

\footnotetext{
${ }^{4}$ It is worth highlighting the consequences of building this database using currently available commercial data as its main source. The first consequence is that I have had to rely on Crazy Jazz's criteria when it comes to defining what is relevant. In terms of revenues, low-selling albums might not be included, although they may well have reflected important relationships at their time. Additionally, Crazy Jazz's commercial classification of what jazz is may differ substantially from the viewpoints of other members of the jazz community. These sampling constraints underline the exploratory status of this paper. See DiMaggio (1987) on classification problems in art, as well as proposed solutions using network analysis.

${ }^{5}$ In future investigations I intend to turn to a direct analysis of recording sessions in order to eliminate the distortions I experienced with the LP titles.
} 


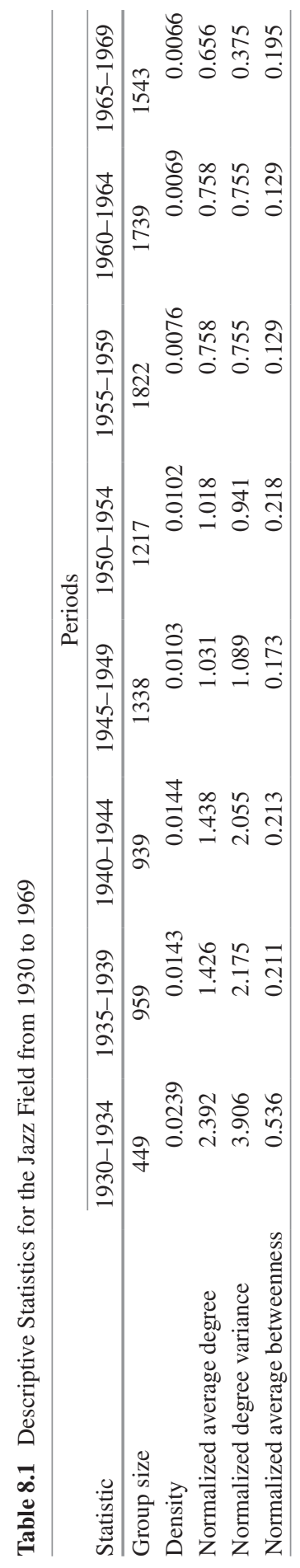




\section{Analytical Strategy}

\section{Classifying Trajectories}

My first concern was to gain an understanding of different trajectory types by examining relevant factors. I selected three aspects: lifespan, average betweenness centrality, and the number of periods of membership in the network's core. In this section I explore each of these dimensions in turn.

Probably the most critical indication of an artist's success is the ability to earn an adequate income in the chosen artistic field. Zuckerman, Kim, Ukanwa, and Rittman (2003) show how novice film actors frequently submit themselves to typecasting in order to establish a foothold in the industry. Even if an artist is able to enter the industry, survival is never entirely guaranteed, because fads and shifts in fashion can impact an artist's fate (Hirsch, 1972/2011). Hence, one's lifespan is a measure of success in a networked industry.

Better connections with other players increase the likelihood of an artist being able to exploit resources. On the other hand, higher coupling to the industry structure can constrain the artist's action and creativity. Nonetheless, more resources and information generally increase the odds of an artist being employed in the most attractive opportunities (Granovetter, 1973/2011). The method I chose to measure the resources available to an individual was to calculate the average betweenness centrality across his or her lifespan in the field because it indicates the extent to which an actor functions as a broker for a network's paths (Hanneman, 2001).

Kadushin (2004) observes that the stability of a field can be grasped by the composition of a network's core. A polarized core can trigger social changes. Core membership empowers its holders to influence a field's rules. Core members are able to establish a consensus among different actors. Conversely, membership in the core provides the opportunity to disrupt the current consensus and to fight to establish new rules. It can be asked whether membership in a network's core does not automatically entail a high betweenness centrality, making dimensions such as betweenness and core membership redundant. This correlation would be high for star networks in which the center is occupied by a single member and all peripheral actors are connected only to the center. In more decentralized networks, peripheral actors might control critical resources despite their positions. Conversely, novice actors might have a very early opportunity to develop a project with a core actor. In doing so, they would become central actors as well. However, if their only connection is to their "godfather" at the core, they have relatively less freedom of action than better connected peripheral actors.

I performed a K-means cluster analysis using the variables average betweenness centrality, lifespan (periods), and number of periods at the core to obtain six clusters of musicians (see Table 8.2). The limitation of the period of analysis to the years 1930-1969 resulted in left and right censoring effects, given that it therefore did not encompass the entire history of jazz. For instance, the trajectory of a musician that began in 1925 would have a longer lifespan than the trajectory captured in my analysis. In order to mitigate left and right censoring effects, I excluded from the trajec- 
Table 8.2 K-means cluster analysis of trajectories

\begin{tabular}{lcccccc}
\hline & \multicolumn{7}{c}{ Cluster } \\
\cline { 2 - 8 } Key trajectory variables & \multicolumn{1}{c}{1} & \multicolumn{1}{c}{3} & \multicolumn{1}{c}{4} & \multicolumn{1}{c}{6} \\
\hline Average betweenness centrality & 0.29 & 0.03 & 0.98 & 0.52 & 2.80 & 0.13 \\
Lifespan (periods) & 6.55 & 1.16 & 6.63 & 3.88 & 6.40 & 3.69 \\
Number of periods at the core & 0.70 & 0.02 & 3.89 & 2.26 & 1.80 & 0.21 \\
Number of individuals & 180 & 3614 & 71 & 128 & 5 & 725 \\
\hline
\end{tabular}

tory analysis those musicians who consistently had decreasingly betweenness centrality as of period one, and those who had consistently increasing betweenness centrality up to period eight. I included these in the Clusters 7 and 8, respectively (see Table 8.2 for the number of musicians in each cluster). Looking at Table 8.2, one can distinguish different types of trajectories and propose some tentative classifications:

Cluster 1: Ivory Tower. Cluster 1 presents the second longest lifespan (6.55 periods); however, it has a low presence in the core (0.7) and average betweenness is only 0.29 . This suggests a group of musicians who are able to sustain themselves in the network, but have limited involvement with both the core and with other musicians. Examples of musicians in this cluster are Duke Ellington and Ella Fitzgerald.

Cluster 2: Wanna-be. Musicians in Cluster 2 present the lowest betweenness average (0.03), lowest lifespan (1.16), and lowest membership in the core (0.02). Unsurprisingly, it is also the largest cluster, with 3614 musicians. This is the typical fate of novice musicians: After a few appearances and slammed doors, they choose to leave the industry.

Cluster 3: Elite. This cluster has the longest average lifespan (6.63 periods) and the highest presence at the core ( 3.89 periods). It also has the second highest average betweenness centrality. I labeled the musicians "elite" because of their low number (only 73 musicians), their long presence in the network, and high core presence. Examples of musicians in this cluster are Dizzy Gillespie, Louis Armstrong, Miles Davis, and Stan Getz. Cluster 4: Shooting Stars. Members of this cluster have half the Elite's average betweenness (0.52) and medium lifespan (3.88). However, they have the second highest core membership (2.26), higher than those in the Ivory Tower cluster, who presented a longer time in the network. This suggests that members of Shooting Stars, though able to remain at the core for a significant portion of their lifespan (almost $60 \%$ of their lives), are unable to maintain their positions for as long as Elite musicians. Remarkable examples of Shooting Stars are Charlie Parker and Artie Shaw, both of whose trajectories ended prematurely.

Cluster 5: Ivy League. There are only a handful of members (five) in this cluster. However, they share some interesting characteristics with other trajectory types. Like their Ivory Tower and Elite colleagues, they have a long lifespan (6.4) and a medium level of membership in the core (1.8), but the highest average between- 
ness centrality. It is worth mentioning them by name: Benny Goodman, Henry "Red" Allen, Sidney Bechet, Don Byas, and Woody Herman. These are founders of swing music who were able to survive in the network. In contrast to Louis Armstrong, who knew how to reposition himself at the core, these players remained on the outskirts of the core. Although not always in the core spotlight, recording with these players was just as coveted as playing with Elite musicians.

Cluster 6: Up-Starters. This is the second largest group (725 musicians), with an average lifespan similar to Shooting Stars. However, their average betweenness and membership in the core are low ( 0.13 and 0.21 , respectively), higher only than the Wanna-be cluster. I identified important musicians in this cluster, including the likes of Dave Brubeck and Quincy Jones. Nonetheless, this may indicate that musicians who were commercially successful were not necessarily active at the core of the jazz community during their heyday.

I would like to point out some potential issues with the Elite and Shooting Stars clusters. Both groups spent an average $60 \%$ of their lifespans in the core, a statistic that suggests the existence of different generations. Failure to distinguish between generations might lead to poorer comprehension of the trajectory of different musicians. For this reason, I split these two clusters into two generations using a 2-mode faction search. The Elite first generation spans from 1930 to 1944 (Cluster 31), while the second generation spans from 1945 to 1969 (Cluster 32). The Shooting Star first generation runs from 1930 to 1949 (Cluster 41), while the second generation runs from 1950 to 1969 (Cluster 42). See Table 8.3 for descriptive statistics on these new clusters. Table 8.4 summarizes the evolution of musicians by each trajectory type.

\section{Blockmodeling the Jazz Field}

In order to obtain a topology of the jazz field structure over time, I applied a blockmodeling approach from the social networks analysis tradition. The use of blockmodeling has become widespread in organizational research. DiMaggio (1986) was

Table 8.3 Clusters Obtained by Splitting Elite and Shooting Star Groups

\begin{tabular}{lcccr}
\hline & \multicolumn{4}{c}{ Clusters } \\
\cline { 2 - 5 } Key trajectory variables & 31 & 32 & 41 & 42 \\
\hline Average betweenness centrality & 1.29 & 0.84 & 0.51 & 0.52 \\
Lifespan (periods) & 7.14 & 6.41 & 3.74 & 3.94 \\
Periods at the core & 4.00 & 3.84 & 2.15 & 2.30 \\
Number of individuals & 22 & 49 & 39 & 89 \\
\hline
\end{tabular}

Note. Cluster 3 (Elite) split into first generation (1930-1944) Cluster 31 (Elite-1) and second generation (1945-1969) Cluster 32 (Elite-2). Cluster 4 (Shooting Star) split into first generation (1930-1949) Cluster 41 (Shooting Star-1) and second generation (1950-1969) Cluster 42 (Shooting Star-2). (Design by the author) 
Table 8.4 Evolution of trajectory types in the Jazz field

\begin{tabular}{|c|c|c|c|c|c|c|c|c|}
\hline $\begin{array}{l}\text { Type of } \\
\text { trajectory }\end{array}$ & $\begin{array}{c}1930- \\
1934\end{array}$ & $\begin{array}{c}1935- \\
1939\end{array}$ & $\begin{array}{c}1940- \\
1944\end{array}$ & $\begin{array}{c}1945- \\
1949\end{array}$ & $\begin{array}{c}1950- \\
1954\end{array}$ & $\begin{array}{c}1955- \\
1959\end{array}$ & $\begin{array}{c}1960- \\
1964\end{array}$ & $\begin{array}{c}1965- \\
1969\end{array}$ \\
\hline & \multicolumn{8}{|c|}{ Trajectory type musicians per period } \\
\hline 1 & 70 & 118 & 144 & 132 & 119 & 142 & 106 & 105 \\
\hline 2 & 188 & 519 & 418 & 622 & 497 & 930 & 881 & 142 \\
\hline 5 & 5 & 4 & 4 & 4 & 4 & 3 & 3 & 1 \\
\hline 6 & 64 & 181 & 237 & 394 & 382 & 442 & 350 & 207 \\
\hline 7 & 74 & 41 & 16 & 10 & 7 & 7 & 7 & 5 \\
\hline 8 & 9 & 38 & 26 & 40 & 53 & 124 & 232 & 957 \\
\hline 31 & 17 & 19 & 20 & 21 & 18 & 20 & 19 & 15 \\
\hline 32 & 13 & 23 & 42 & 47 & 47 & 49 & 44 & 40 \\
\hline 41 & 6 & 10 & 12 & 17 & 23 & 28 & 27 & 21 \\
\hline 42 & 3 & 6 & 20 & 51 & 67 & 76 & 70 & 50 \\
\hline \multirow[t]{2}{*}{ Total } & 449 & 959 & 939 & 1338 & 1217 & 1821 & 1739 & 1543 \\
\hline & \multicolumn{8}{|c|}{ Percentage of trajectory type per period } \\
\hline 1 & $16 \%$ & $12 \%$ & $15 \%$ & $10 \%$ & $10 \%$ & $8 \%$ & $6 \%$ & $7 \%$ \\
\hline 2 & $42 \%$ & $54 \%$ & $45 \%$ & $46 \%$ & $41 \%$ & $51 \%$ & $51 \%$ & $9 \%$ \\
\hline 5 & $1 \%$ & $0 \%$ & $0 \%$ & $0 \%$ & $0 \%$ & $0 \%$ & $0 \%$ & $0 \%$ \\
\hline 6 & $14 \%$ & $19 \%$ & $25 \%$ & $29 \%$ & $31 \%$ & $24 \%$ & $20 \%$ & $13 \%$ \\
\hline 7 & $16 \%$ & $4 \%$ & $2 \%$ & $1 \%$ & $1 \%$ & $0 \%$ & $0 \%$ & $0 \%$ \\
\hline 8 & $2 \%$ & $4 \%$ & $3 \%$ & $3 \%$ & $4 \%$ & $7 \%$ & $13 \%$ & $62 \%$ \\
\hline 31 & $4 \%$ & $2 \%$ & $2 \%$ & $2 \%$ & $1 \%$ & $1 \%$ & $1 \%$ & $1 \%$ \\
\hline 32 & $3 \%$ & $2 \%$ & $4 \%$ & $4 \%$ & $4 \%$ & $3 \%$ & $3 \%$ & $3 \%$ \\
\hline 41 & $1 \%$ & $1 \%$ & $1 \%$ & $1 \%$ & $2 \%$ & $2 \%$ & $2 \%$ & $1 \%$ \\
\hline 42 & $1 \%$ & $1 \%$ & $2 \%$ & $4 \%$ & $6 \%$ & $4 \%$ & $4 \%$ & $3 \%$ \\
\hline Total & $100 \%$ & $100 \%$ & $100 \%$ & $100 \%$ & $100 \%$ & $100 \%$ & $100 \%$ & $100 \%$ \\
\hline
\end{tabular}

Note. Cluster 1: Ivory Tower; Cluster 2: Wanna-be; Cluster 5: Ivy League; Cluster 6: Up-Starters; Cluster 31: Elite, first generation (1930-1944), Cluster 32: Elite, second generation (1945-1969); Cluster 41: Shooting Star, first generation (1930-1949); Cluster 42: Shooting Star, second generation (1950-1969). (Design by the author)

one of its first proponents and used the approach to study the relation among theater managers in the United States. Other seminal works using blockmodeling are Mohr's study (1994) of non-profit organizations at the beginning of the twentieth century, and Padget and Ansell's (1993) investigation of relationships among Florentine families in order to understand the rise of the Medici. The idea behind blockmodeling is to group together those individuals who share similar patterns of relationships with other individuals in the network (see Breiger, 2004, for a review of the methodology). As a result, musicians placed in the same block will be structurally similar, meaning that they will be likely to display the same pattern of ties to other actors in the network. Nevertheless, structurally similar actors are not necessarily connected.

There are several methodologies for obtaining block models from a given network (for a review, see Ferligoj, Doreian, \& Batagelj, 2011). CONCOR 
(CONvergence of iterated CORrelations) is the oldest and works as follows: First the algorithm calculates the correlation between each pair of actors in a series of iterations. The aim is to identify those actors with the highest likeliness of ties. Then, based on the matrix of correlations, it splits the network into two partitions. I chose to split the network three times, thereby obtaining eight blocks. As Hanneman (2001) indicates, there is no good or bad number of blocks. I chose eight blocks because this number would yield a less complex output.

I used UCINET 6.64, a network analysis software, to obtain a permutated matrix and its respective image matrix. The image matrix is obtained from the permuted matrix by calculating the density of ties in each block. Next, I dichotomized the density matrix of each period using the following procedure: If the density of a given block was above the average density of the image matrix, I considered a tie to exist between a pair of blocks (represented as a solid line in Fig. 8.1a-h). If the density of a block was between the average density and half of this value, I considered this a weaker tie (represented by a dashed line in Fig. 8.1a-h). In the case of diagonal blocks (reflexive relationships), the higher the density, the higher the likeliness of including a cohesive group of musicians.

Figure 8.1a-h show the results of this blockmodeling of the jazz musician networks. I also identified the most important blocks for each trajectory type as follows: Whenever the percentage of a particular trajectory type was above $12.5 \%$ (the expected percentage average per block, given the eight blocks generated by CONCOR), I identified the number of musicians from that category who are members of that block. Furthermore, in order to increase the clarity of the schemes, I left blank isolated blocks with no relevant trajectory type.

\section{Relationships Between Trajectory Types}

In order to understand the relations between the trajectory types over time, I built density matrices for each period, associating pairs of trajectory types. In an approach similar to the blockmodeling exercise, I obtained an image matrix (see Fig. 8.2a-h). This image matrix is dichotomized: Above average density is marked "1," while below average density is marked " 0 ."

Several phenomena can become evident through this analysis. First, it is possible to ascertain to whom each trajectory type was related during each period. Some of the questions I address with this approach, therefore, are how Elite Cluster members interact and whom an emerging Elite member dealt with before attaining a dominant position. Second, in a strictly regulated society where social roles are highly differentiated, role types cannot freely interact with one another. The less differentiated a society (i.e., interactions between individuals are mainly driven by the social norms embedded in social roles), the more outbound are the ties observable between groups. From this perspective, the greater the number of ties, the less differentiated one trajectory type is from another. Third, by analyzing the sociograms generated by the dichotomized matrixes it is possible to identify which trajectory types are 


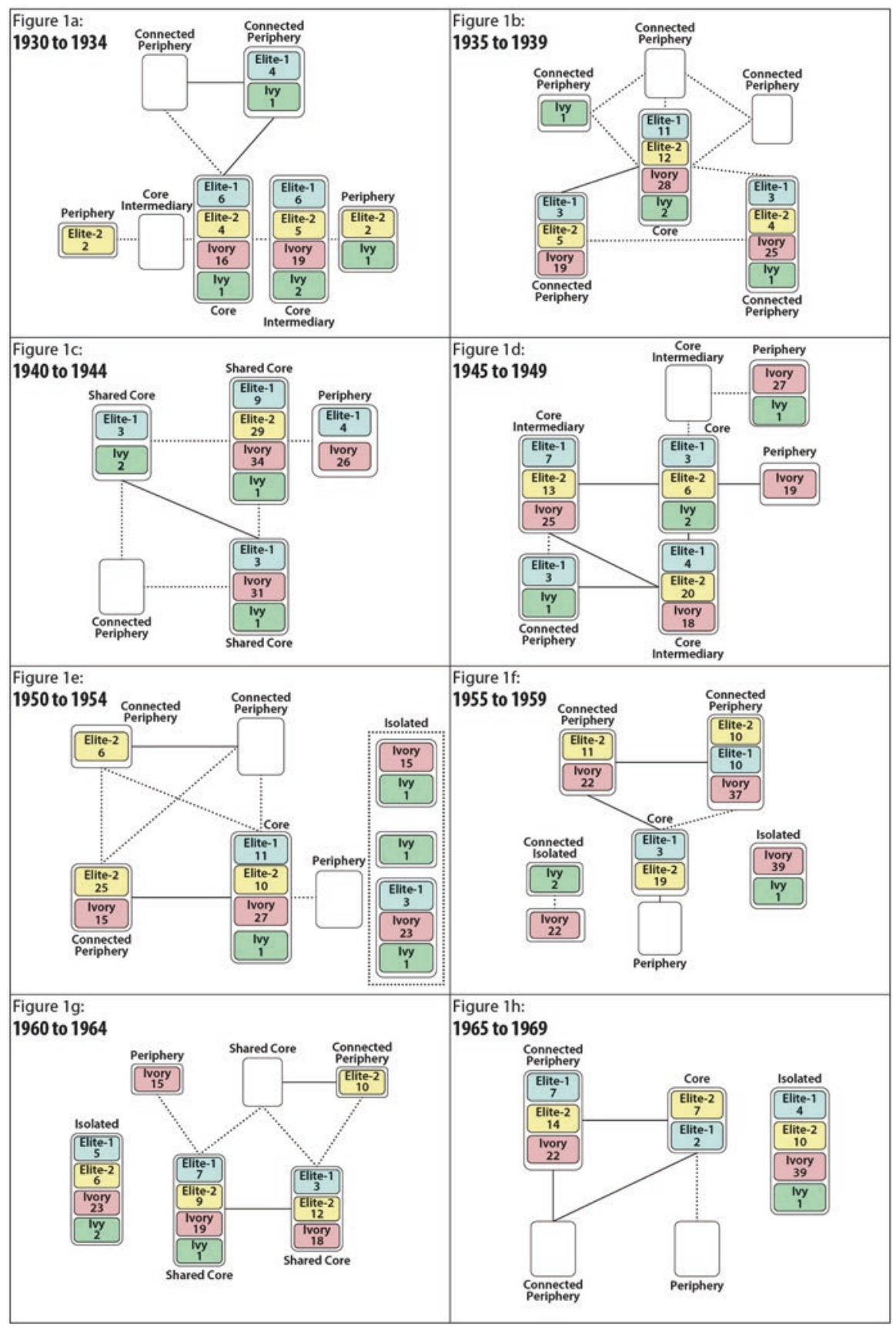

Fig. 8.1 CONCOR blocks per studied period (Design by author) 


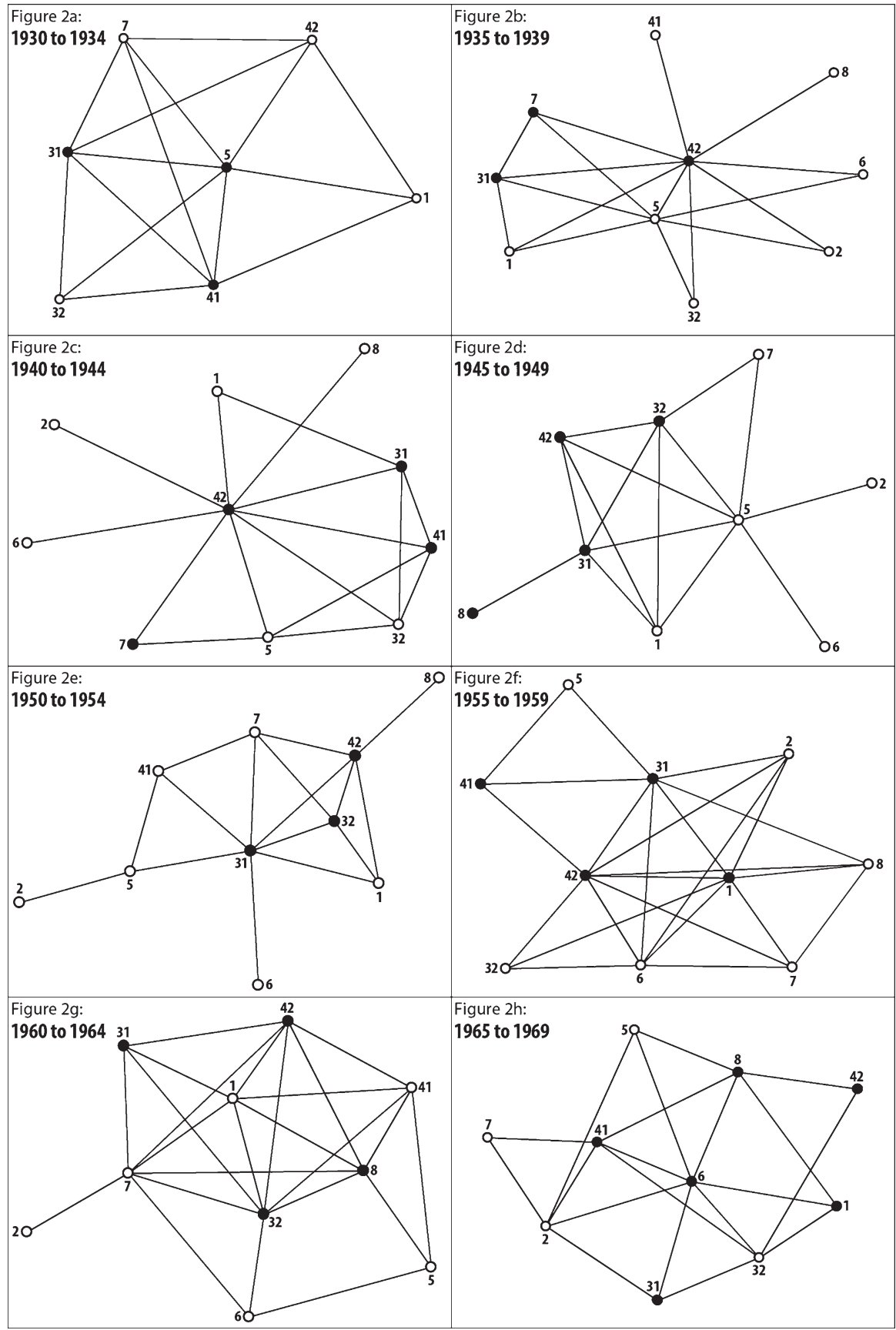

Fig. 8.2 Evolution of ties among trajectory types in the Jazz Field. Cluster 1: Ivory Tower; Cluster 2: Wanna-be; Cluster 5: Ivy League; Cluster 6: Up-Starters; Cluster 31: Elite-1, first generation (1930-1944), Cluster 32: Elite-2, second generation (1945-1969); Cluster 41:Shooting Star-1, first generation (1930-1949); Cluster 42 Shooting Star-2, second generation (1950-1969). Black nodes $=$ cohesive groups; white nodes $=$ non-cohesive groups. (Design by author) 
Table 8.5 QAP matrix Pearson Correlation between periods

\begin{tabular}{|c|c|c|c|c|c|c|c|c|}
\hline \multirow[b]{2}{*}{ Period } & \multicolumn{8}{|c|}{ Period } \\
\hline & $\begin{array}{c}1930- \\
1934\end{array}$ & $\begin{array}{c}1935- \\
1939\end{array}$ & $\begin{array}{c}1940- \\
1944\end{array}$ & $\begin{array}{c}1945- \\
1949\end{array}$ & $\begin{array}{c}1950- \\
1954\end{array}$ & $\begin{array}{c}1955- \\
1959\end{array}$ & $\begin{array}{c}1960- \\
1964\end{array}$ & $\begin{array}{c}1965- \\
1969\end{array}$ \\
\hline $\begin{array}{l}1930- \\
1934\end{array}$ & 1 & & & & & & & \\
\hline $\begin{array}{l}1935- \\
1939\end{array}$ & 0.186 & 1 & & & & & & \\
\hline $\begin{array}{l}1940- \\
1944\end{array}$ & 0.295 & $0.434 *$ & 1 & & & & & \\
\hline $\begin{array}{l}1945- \\
1949\end{array}$ & $0.405^{*}$ & $0.691 * * *$ & $0.386^{*}$ & 1 & & & & \\
\hline $\begin{array}{l}1950- \\
1954\end{array}$ & $0.473 * *$ & $0.46 * *$ & 0.371 & $0.754 * * *$ & 1 & & & \\
\hline $\begin{array}{l}1955- \\
1959\end{array}$ & -0.027 & $0.354 * *$ & $0.306^{*}$ & 0.092 & $0.406^{* *}$ & 1 & & \\
\hline $\begin{array}{l}1960- \\
1964\end{array}$ & 0.036 & -0.163 & $0.364 * * *$ & 0.117 & $0.405 * * *$ & 0.189 & 1 & \\
\hline $\begin{array}{l}1965- \\
1969\end{array}$ & $-0.289 * *$ & -0.132 & -0.163 & -0.058 & 0.004 & -0.089 & $0.333 * *$ & 1 \\
\hline $\begin{array}{l}1930- \\
1934\end{array}$ & 1 & & & & & & & \\
\hline
\end{tabular}

Note $* p<.05 ; * * p<.01 ; * * * p<.001$

Two-tailed tests.

central, which roles are peripheral, and which trajectory types play a brokerage role. The results of this analysis are shown in Fig. 8.2a-h. I have left the original cluster numbering visible on the sociograms. White nodes denote below-average-density cells, which can be interpreted as groups with low cohesiveness.

I also verified how similar each period was to any other period of time. Webster, Freeman, and Aufdemberg (2001) argue that actors in similar social contexts will establish similar network patterns. Following this analytical approach, I used Ucinet's QAP Matrix tool to obtain a matrix of Pearson correlations among all periods (Table 8.5). The diagonal under the main diagonal (with $1 \mathrm{~s}$ ) represents the correlations between subsequent periods. Given the high incidence of right and left censored trajectories in the periods 1930-1934 and 1965-1969, I warn against possible misinterpretations of the very low Pearson correlation at both extremes of this diagonal. Hence, I excluded Clusters 7 and 8 (left and right-censored trajectories) from this analysis in order to mitigate their phasing out and phasing in effects. 


\section{Results: The History of Jazz from a Structural Perspective}

\section{The Pre-swing Era: 1930 to 1934}

In the early thirties, jazz was considered a dead style, alive only in the memories of connoisseurs nostalgic for a pre-Depression America (Lopes, 2002). "Sweet" bands, headed by classical-music-educated maestros such as Paul Whiteman, controlled the emerging phonographic industry of the period. Nonetheless, some sidemen musicians such as Benny Goodman, who played for big bands and had contact with early jazz musicians, started to introduce "hot" elements. The musical style they were developing would be eventually called swing. It is worth noting that more than $90 \%$ of the recording sessions were concentrated in three cities: New York, Chicago, and London (Fig. 8.3). This geographic concentration was reinforced by the recording industry structure.

It is evident that during this period Ivory Tower and Ivy League musicians dominated the network's core (Fig. 8.1a in the Core and Core Intermediary blocks). Both generations of the Elite Cluster were already present, but they played a minor role, which can be observed by the limited number of musicians in these categories (Table 8.4). In Fig. 8.4 it is apparent that betweenness centrality was higher than degree centrality, indicating that few musicians were instrumental in playing the role of brokers.

Figure $8.2 \mathrm{a}$ shows the relationship between trajectory types. It is interesting to observe that despite the large number of ties between trajectory types, only three

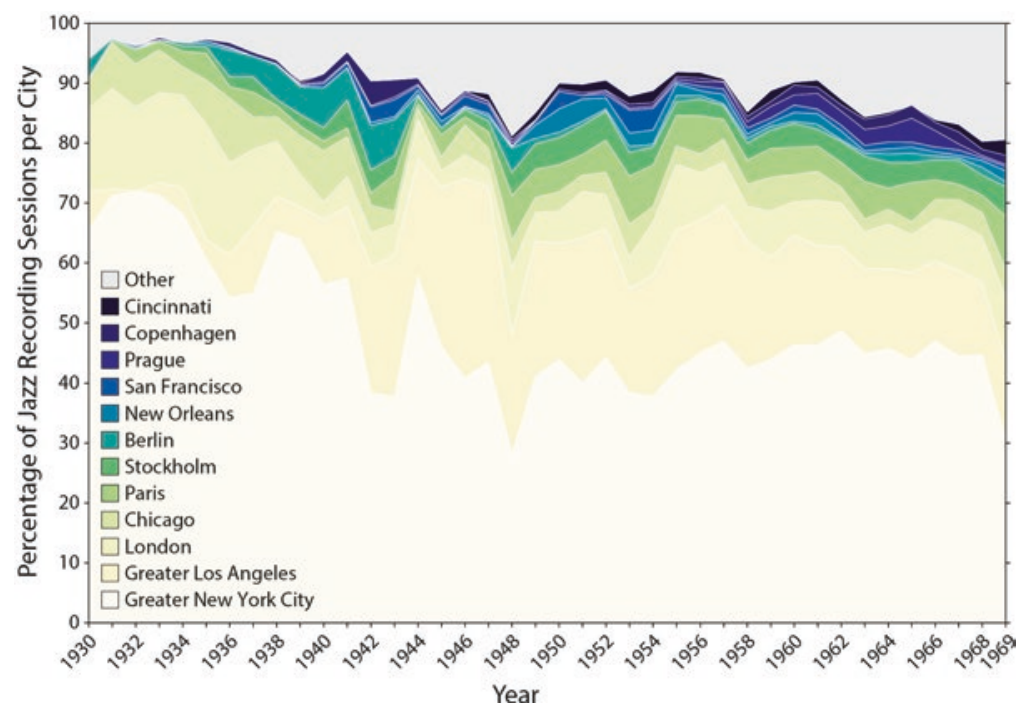

Fig. 8.3 Distribution of recording sessions by major city (Design by author) 


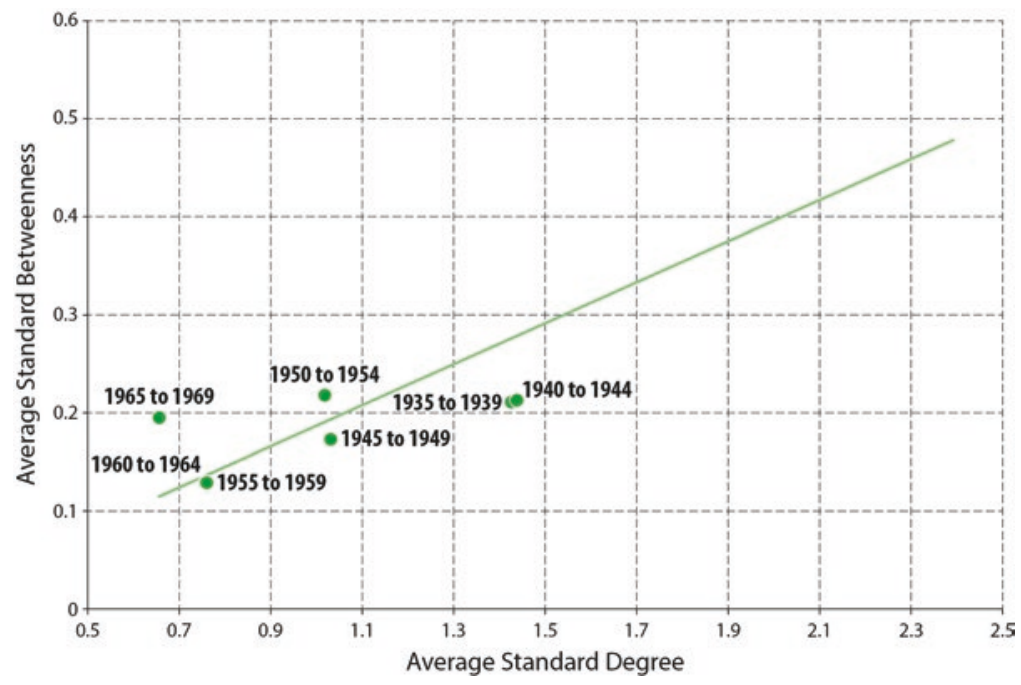

Fig. 8.4 Evolution of centrality measures: degree and betweenness (Design by author)

groups are cohesive: Elite-1, Ivy League, and Shooting Star-1. Elite-1 and Ivy League clearly occupy a central role vis-à-vis other trajectory types, suggesting that those two groups played a coordinating role in this field.

\section{The Swing Era: 1935-1945}

The consolidation of swing as a popular style came in the late 1930s. The popularity of its musicians enabled them to bridge racial chasms, as exemplified by Goodman's partnership with Teddy Wilson. A close connection with a monopolistic recording industry also helped structure a centralized organizational field. As Peterson and Anand (2002) observe, in the mid-1940s the phonographic field in the United States migrated from a normative to a competitive model. Several explanations exist for this shift. The first relates to the domain of law and regulation. The founding of Broadcast Music, Inc (BMI) in 1942 broke the American Society of Composers and Publishers' (ASCAP) monopoly on music royalty distribution agreements and permitted the shift from the New York Tin Pan Alley formula to the introduction of new styles (Hobsbawm, 1989; Peterson \& Anand, 2002). The number of recording sessions fell dramatically in 1942 (see Fig. 8.5), which had the effect of loosening the leadership of established swing musicians.

An inspection of the geographic distribution of the sessions reveals that New York and Los Angeles still accounted for the majority in the mid-1940s. However, there was a clear shift from New York to Los Angeles due to the usage of jazz in movies (Fig. 8.3). In Europe, jazz declined in London, but expanded in pre-World-War-II 


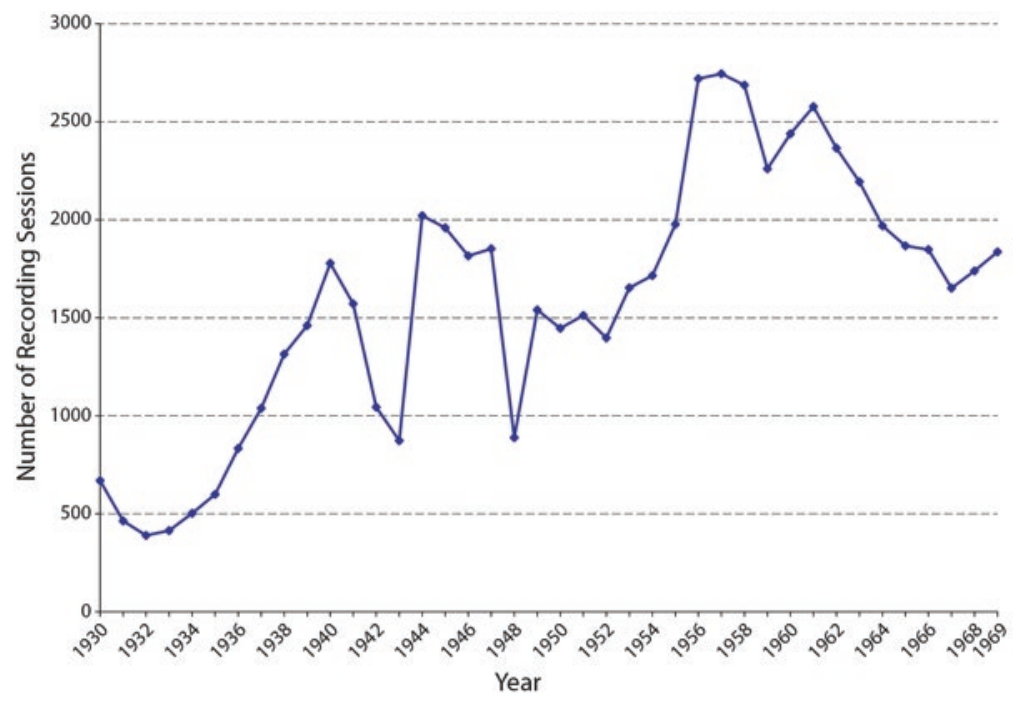

Fig. 8.5 Evolution of recorded jazz sessions included in the sample (Design by author)

Germany. After the 1942-1944 musicians' strike against the recording industry in the United States ended the number of recording sessions soared (see 1944 in Fig. 8.3). Due to World War II, though, this recovery mainly occurred in the United States, while the European share dwindled (see Fig. 8.5).

The shift from a normative to a competitive field is observed in the field articulation. Figure 8.4 indicates that the periods $1935-1939$ and 1940-1944 both have low betweenness and high degree centrality (a combination typical of more cohesive networks). In this type of configuration, brokerage is less important. The loose articulation of the field, along with the presence of experienced sidemen, was a crucial ingredient in the subsequent revolution of the jazz field. Nonetheless, older generations still controlled the field. A low QAP (Quadratic Assignment Procedure) correlation is observable between period 1 (1930-1934) and period 2 (1935-1939) (Table 8.5 ). This may be explained by a structural change in the network. As cohesion increased, so concentric paths became established. In contrast, the patterns of relationships did not change dramatically from period 2 (1935-1939) to period 3 (1940-1944) (Table 8.5 shows a 0.43 Pearson correlation, similar to Webster et al.'s (2001) level). This suggests that with the articulation in the 1935-1940 period relationships changed at a slower pace.

In Fig. 8.1b a Core block articulating the field's record production is quite clear. Ivory Tower musicians predominated over other trajectory types (Fig. 8.1b). Nonetheless, a connected periphery started to emerge, which balanced the dominance of the core. In Fig. 8.1c the emergence of shared Core blocks can be seen. Ivory Tower, Ivy League, and Elite-1 musicians were still controlling the field. There was, however, no clear-cut core articulating the entire structure. It is worth 
noting that 29 musicians from Elite-2 (or $75 \%$ of this generation) were already present in the field, all concentrated in a single block.

Figure $8.2 \mathrm{~b}, \mathrm{c}$ reveal details of interactions between trajectory types. Shooting Star-2 musicians (Cluster 42) came to dominate the interactions in both periods. In view of the fact that Shooting Star musicians experienced short periods at the core, my findings suggest that in parallel to the institutionalization of swing most interactions were articulated by players with lower permanence in the network. It is also worth noting that despite the concentration of all Elite-2 musicians in the same block (as pointed out for Fig. 8.1c) they were not cohesive as a trajectory type (Fig. 8.2c). As a possible interim interpretation, I suggest that their relationships during this period were not best captured within the phonographic industry, but in more informal, less commercial, uncoupled locations such as jam sessions and night clubs (Becker, 2004).

\section{The Bop/Cool Era: 1945 to 1960}

Peterson and Anand (2002) note that by the mid-1940s a new Federal Communication Commission (FCC) regulation had broken the monopoly held by the major radio stations. Furthermore, in 1948 there was a second musicians' strike in the U.S. recording industry, leading to a general decline in recording sessions (see Fig. 8.5). The emergence of television networks also impacted the radio industry. Companies shifted their advertising budgets toward television, causing the radio networks to view smaller and local radio stations as unattractive. Both factors-the end of the radio stations' monopoly and the emergence of television networks-led to the sale of licenses to local entrepreneurs. As a result, a flood of new licenses were issued to local radio stations, which had few resources to invest in live shows. Instead, they played albums published by small recording companies, increasing the diversity of styles reaching the public (Peterson \& Anand, 2002, p. 268). With this change, promoters of new styles were able to challenge the dominance of established musicians. It is worth noting that when the number of recording sessions did once again increase again the strike (see 1950 in Fig. 8.5), New York and Los Angles were unable to retain the geographic concentration they had held during World War II.

In the mid-1950s this picture changed as young America embraced rock. Jazz as an embracing paradigm lost touch with a large share of the American audience, resulting in its loss of dominance to rock music in the sales charts published in Billboard magazine. In spite of these changes, demand for jazz recording sessions was still rising at the end of the 1950s (see Fig. 8.5). Although the New York scene did remain stable, most of the growth came from Los Angeles and European-based recording sessions (see Fig. 8.3). These changes in the industry and the demographics of jazz musicians accelerated the shift from the normative to the competitive configuration.

To be sure, relationships across periods were reasonably stable (see Table 8.5, correlations were around 0.4). Furthermore, an examination of the field's block- 
model structure (Fig. 8.1d-f) shows the stability of a core and connected periphery configuration, reinforcing the idea of a fairly cohesive field. Yet in Fig. 8.4 a slight shift from the superiority of degree centrality towards betweenness centrality is detectable. When the field reaches the 1955-1959 period, there is a relative equilibrium between the average betweenness centrality and the average degree centrality, indicating that the field was swinging back towards a more centralized configuration.

Elite-2 musicians, mostly associated with the emerging bop style, were important players from 1945 to 1960. In Fig. 8.1d it is evident that Elite-2 musicians dominated the core, partially displacing Ivory Tower and Elite-1 musicians to the periphery or to the outskirts of the core. Nonetheless, in an increasingly open system as the phonographic field was becoming (Perrow, 1986, pp.178-218), uncontested dominance was not guaranteed. During the following period, from 1950 to 1954, Elite-2's dominance of the core was shared with Elite-1 and Ivory Tower (Fig. 8.1e).

It was first during the 1945-1949 period that Elite-1 and Elite-2 trajectory musicians became more prominent than other trajectory types (Fig. 8.2d). This prominence was maintained throughout the ensuing period (Fig. 8.2e). Although Shooting Star trajectory musicians had been prominent during the previous period (see Fig. 8.1c), they were now pushed into a more peripheral role.

However, the leadership of Elite-2 members was not sustained for long: It soon became a dispersed and low cohesion group (Fig. 8.2f). Although Elite-2 musicians were still central (Fig. 8.1f), they showed low levels of collaboration among themselves, spending more effort in exploring outbound relationships. In contrast, those in the Elite-1 and Ivory Tower clusters, along with both generations of Shooting Stars, were the only cohesive groups in this period. These findings have several implications. In the previous period, Shooting Star musicians were central in the interactions (Fig. 8.2b, c), but Elite and Ivory Tower musicians dominated the most prominent blocks (Fig. 8.1b, c). Now, however, Elite musicians were both central in the interactions (Fig. 8.2d-f) and dominant in the Core blocks (Fig. 8.2d-f).

\section{The Jazz Renaissance: 1960-1969}

During the 1960s, jazz became increasingly associated with the "older generation," and its decline quickened (see Fig. 8.5). In response to this downturn several musicians looked for outside the traditional canon for ways to reinvigorate that field of music. For instance, Miles Davis introduced fusion, while Stan Getz helped bring Bossa Nova to American jazz. All these efforts to mitigate jazz's decline led to an increasingly loosely coupled field. To be sure, there was abundant reaction to disqualify some of these new idioms. Miles Davis's fusion was thought to be more a style of rock than of jazz, while Coleman's free jazz was unacceptable to some traditional jazz musicians. Geographically, this period also represents a sharp decline in the U.S.-centrism of jazz. The large American cities cited in Fig. 8.3 represented 
$71 \%$ of recording sessions in 1960, falling to $54 \%$ by 1969 . By contrast, the large European cities cited in Fig. 8.3 had 19\% of recording sessions in 1960, but rising to $27 \%$ towards 1969 .

Jazz scholars identify this period as strongly fragmented because of the adoption of distinct styles. Figure 8.4 shows that the average betweenness centrality during this period is higher than the average degree centrality, indicating higher reliance on brokers. With greater stylistic differentiation emerging, musicians can be expected to play increasingly among peers sharing the same style. The shift from the more cohesive configuration seen in the1945-1960 period to the less cohesive configuration of the 1945-1960 period is also accompanied by a stark change in the pattern of relationships (see Table 8.5 for the statistically non-significant correlation between the 1955-1959 and 1960-1964 periods).

Figure 8.1g shows the division of the field's core into two, nonetheless interconnected, shared cores. In other words, although musicians were going in different directions, the process cannot be termed fragmentation, because the field's blocks remain connected. Elite musicians (from both generations) are represented occupying the shared Core blocks together with Ivy League musicians. Figure 8.2g reveals a rearticulation of Elite-2 from 1960 to 1964, with the cluster occupying a more central role, articulated with Shooting Star-2 and Elite-1.

In the period from 1965 to 1969 , the network was relatively stable in comparison to other periods (see Table 8.5, 0.333 correlation across periods), while the tendency for further prominence of brokerage over cohesion was still operating. Table 8.1 indicates that the average betweenness centrality is higher than the average degree centrality. In comparison to the previous period, a clearer core-periphery configuration (Fig. 8.1h) is seen.

During this period, several Elite-2 musicians were present at the core (Fig. 8.1h). As a group, though, Elite-2 became less cohesive (Fig. 8.2h). New groups emerged as central and cohesive, like Cluster 6, the Up-Starters (Fig. 8.2h). It is worth noting that Elite-2 was neither able to entirely displace older groups nor become a perennial cohesive group. In addition, Fig. 8.2h shows a return of Elite-1, although the expectation would be for the core to be held by the newly established generation. This evidence suggests that, given a stylistic crisis in the field, previous Elite generations were able to fill the void left by the competing new generation.

\section{Discussion}

The above analysis reveals a rearrangement in the field structure. While the field was relatively centralized (both geographically and socially) during the 1930-1934 period, it became more cohesive in the following periods, regaining a higher centralization toward the 1965-1969 period (Fig. 8.4). In broad strokes, this is observable throughout the different blockmodeling configurations (Fig. 8.1a-h). A clear core-periphery structure is discernible during the 1930-1934 period, with the peripheral blocks becoming more connected throughout the coming periods, and 
shared core positions emerging. Peripheral blocks remain connected, despite the higher centralization of the 1964-1969 period and the reemergence of a distinct core position.

Hence, it can be inferred that in normative fields there is high centralization and a core-periphery distinction. With a shift to a competitive field, more spontaneous interactions take place, leading to better distribution of interactions throughout the field. The field again attains a higher centralization, possibly due to stylistic differentiation and geographic localism. Yet there is lower core-periphery distinction compared with the 1930-1934 period. $^{6}$

It is evident that Shooting-Star musicians were prominent in the network (Fig. $8.2 \mathrm{~b}, \mathrm{c}$ ) at the dawn of the transition of the jazz field from normative to competitive, In the 1945-1949 period, Elite musicians attained this centrality. However, this achievement of centrality was fairy unstable: Elite musicians across generations displaced each other. Looking at Elite musicians vis-à-vis the blocks in which they are located (Fig. 8.1a-h), it seems, though, that Elite prominence consolidated up to the 1945-1949 period. The distinction between these two sets of analyses sheds light on the value of blockmodeling: While cohesion-based prominence is important (Fig. 8.2a-h), structural equivalence (Fig. 8.1a-h) allows identification of those musicians who dominate blocks analytically constructed to capture asymmetries across relationships. In substantial terms, if individuals who dominate core blocks are not the same as those whose centrality is cohesion-based, it can be inferred that a loosening has occurred between global and local key players. While the global key players might enjoy higher brokerage gains, local key players may be able to command specific styles, fads, and fashions, as suggested by the prominence of musicians with short-timespan trajectories.

In most periods, Elite Cluster musicians dominate the Core blocks in both the normative and competitive field configurations - unsurprising given that this grouping was obtained by clustering together musicians with high betweenness centrality and long lifespan. However, during the reconfiguration years (from 1945 to 1964), the Elite musicians were also prominent in its cohesion-based centrality. Hence, during the transition from one configuration to another, the Elite musicians played both the high-cohesiveness and high-status roles. But when the field became relatively centralized again, and musicians dispersed into distinct styles, younger generations yielded the central position to older musicians.

\section{Conclusions}

Aldrich (1999) suggests that communities evolve in a nested way. He suggests a coevolutionary approach concerned with how sets of populations coevolve over time. From this perspective, trajectories are constrained and supported by a

\footnotetext{
${ }^{6}$ Of course, here I am assuming that the field reached in equilibrium in 1969. Further analyses of right-censored data could show a decline in interperipheral connections.
} 
macro-structure. Conversely, the macro-structure is shaped by the nested microtrajectories. The idea of coevolution can be extrapolated to different levels of analysis: regions, countries, organizations, and individuals. A field's evolution in terms of its structural and normative elements is better explained by describing the coevolution among its members.

This research contributes to the literature in question by showing that changes in the jazz field structure from normative to competitive in the mid-1940s occurred in tandem with significant changes in the positioning of jazz musicians within the network.

This research presents an empirical puzzle: More competitive structures are beneficial for emerging artists because they grant them better access to resources previously concentrated in established musicians' hands. Consequently, the shift from a normative to a competitive field is likely to enhance individual creativity and allow for the emergence of a new elite. However, if the new elite is unable to establish a new normative era and to curtail the competitive forces, its new styles may be quickly put to the test and its central position disputed by even more recently recognized musicians. As a result, the drive for innovation and better positions leads to the weakening of a field's paradigm. Once faced with a crisis and the additional challenge of reestablishing normative controls, newly ensconced musicians are likely to look to previously predominant musicians who still retain social capital and status. A radical shift toward a competitive field is therefore likely to reestablish formerly prevailing musicians in core positions, contrary to a common sense intuition that those musicians would be left to occupy peripheral areas of the network.

Acknowledgments I would like to thank the CAPES (Coordination for the Improvement of Higher Education Personnel) Foundation for the support received.

\section{References}

Abbott, A. (2001). Temporality and process in social life. In A. Abbott (Ed.), Time matters: On theory and method (pp. 209-239). Chicago: The University of Chicago Press.

Accominotti, F. (2009). Creativity from interaction: Artistic movements and the creativity careers of modern painters. Poetics, 37, 267-294. doi:10.1016/j.poetic.2009.03.005

Aldrich, H. E. (1999). Organizations evolving. London: Sage.

Anand, N., \& Peterson, R. A. (2000). When market information constitutes fields: Sensemaking of markets in the commercial music industry [Special issue]. Organization Science, 11, 270-284. Retrieved from http://www.jstor.org/stable/2640261

Barabási, A. L. (2003). Linked: How everything is connected to everything else and what it means for business, science, and everyday life. New York: Plume.

Becker, H. S. (2004). Jazz places. In A. Bennett \& R. A. Peterson (Eds.), Music scenes: Local, translocal, and virtual (pp. 17-27). Nashville: Vanderbilt University Press.

Bourdieu, P. (1993). The field of cultural production. Essays on art and literature. New York: Columbia University Press.

Bourdieu, P. (1996). The rules of art: Genesis and structure of the literary field. Cambridge, UK: Polity Press. 
Breiger, R. L. (2004). The analysis of social networks. In M. Hardy \& A. Bryman (Eds.), Handbook of data analysis (pp. 505-526). London: Sage.

DiMaggio, P. J. (1986). Structural analysis of organizational fields: A blockmodel approach. In B. Staw \& L. Cummings. (Eds.), Research in organizational behavior (Vol. 8, pp. 335-370). Greenwich, CT: JAI Press.

DiMaggio, P. J.(1987). Classification in art. American Sociological Review, 52, 440-455. Retrieved from http://www.jstor.org/stable/2095290

DiMaggio, P. J. (1991). Constructing an organizational field as a professional project: U.S. art museums, 1920-1940. In W. W. Powell \& P. J. DiMaggio (Eds.), The new institutionalism in organizational analysis (pp. 267-292). Chicago: The University of Chicago Press.

DiMaggio, P. J., \& Powell, W. W. (1983). The iron cage revisited: Institutional isomorphism and collective rationality in organizational fields. American Sociological Review, 48, 147-160. Retrieved from http://www.jstor.org/stable/2095101

Dubois, S., \& François, P. (2013). Career paths and hierarchies in the pure pole of the literary field: The case of contemporary poetry. Poetics, 41, 501-523. http://doi.org/10.1016/j. poetic.2013.07.004

Ferligoj, A., Doreian, P., \& Batagelj, V. (2011). Positions and roles. In J. Scott \& P. J. Carrington (Eds.), The SAGE handbook of social network analysis (pp. 434-446). Los Angeles: Sage.

Giuffre, K. (1999). Sandpiles of opportunity: Success in the art world. Social Forces, 77, 815-832. Retrieved from http://www.jstor.org/stable/3005962

Granovetter, M. S. (1973). The strength of weak ties. American Journal of Sociology, 78, $1360-1380$.

Hanneman, R. A. (2001). Introduction to social network methods. Retrieved from http://www. researchmethods.org/NETTEXT.pdf

Hirsch, P. M. (2011). Processing fads and fashions: An organization-set analysis of cultural industry systems. In M. Granovetter \& R. Swedberg (Eds.), The sociology of economic life (3rd ed., pp. 340-356). Boulder: Westview Press. (Original work published 1972)

Hobsbawm, E. J. (1989). The jazz scene. London: Weidenfeld \& Nicolson.

Kadushin, C. (2004). Introduction to social network theory. Unpublished manuscript. Retrieved from http://melander335.wdfiles.com/local--files/reading-history/kadushin.pdf

Kirschbaum, C. (2007). Careers in the right beat: US jazz musicians' typical and non-typical trajectories. Career Development International, 12, 187-201. doi:10.1108/13620430710733659

Leblebici, H., Salancik, G. R., Copay, A., \& King, T. (1991). Institutional change and the transformation of interorganizational fields: An organizational history of the U.S. radio broadcasting industry. Administrative Science Quarterly, 36, 333-363. doi:10.2307/2393200

Lena, J. C., \& Pachucki, M. C. (2013). The sincerest form of flattery: Innovation, repetition, and status in an art movement. Poetics, 41, 236-264. doi:10.1016/j.poetic.2013.02.002

Lopes, P. D. (2002). The rise of a jazz art world. Cambridge, UK: University Press.

Mohr, J. W. (1994). Soldiers, mothers, tramps and others: Discourse roles in the 1907 New York City charity directory. Poetics, 22, 327-357. doi:10.1016/0304-422X(94)90013-2

Padget, J. F., Ansell, C. K. (1993). Robust action and the rise of the Medici, 1400-1434. American Journal of Sociology, 89, 1259-1319

Perrow, C. (1986). Complex organizations. A critical essay. New York: Random House.

Peterson, R. A., \& Anand, N. (2002). How Chaotic Careers Create Orderly Fields. In M. A. Peiperl, M. B. Arthur, \& N. Anand (Eds.), Career creativity: Explorations in the remaking of work (pp. 257-279). Oxford: University Press.

Podolny, J. M. (2001). Networks as the pipes and prisms of the market. American Journal of Sociology, 107, 33-60. doi:10.1086/323038

Rerup, C., \& Feldman, M. S. (2011). Routines as a source of change in organizational schemata: The role of trial-and-error learning. The Academy of Management Journal, 54, 577-610. doi:10.5465/AMJ.2011.61968107

Scott, W. R. (1995). Institutions and organizations. Thousand Oaks: Sage.

Stark, D., \& Vedres, B. (2006). Social times of network spaces: Network sequences and foreign investment in Hungary. American Journal of Sociology, 111, 1367-1411. doi:10.1086/499507 
Webster, C. M., Freeman, L. C., \& Aufdemberg, C. G. (2001). The impact of social context on interaction patterns. Journal of Social Structure, 2. Retrieved from http://www.cmu.edu/joss/ content/articles/volume2/Webster.html

Zuckerman, E. W., Kim, T.-Y., Ukanwa, K., \& von Rittmann, J. (2003). Robust identities or nonentities? Typecasting in the feature-film labor market. American Journal of Sociology, 108, 1018-1074. doi:10.1086/377518

Open Access This chapter is distributed under the terms of the Creative Commons Attribution 4.0 International License (http://creativecommons.org/licenses/by/4.0/), which permits use, duplication, adaptation, distribution and reproduction in any medium or format, as long as you give appropriate credit to the original author(s) and the source, provide a link to the Creative Commons license and indicate if changes were made.

The images or other third party material in this chapter are included in the work's Creative Commons license, unless indicated otherwise in the credit line; if such material is not included in the work's Creative Commons license and the respective action is not permitted by statutory regulation, users will need to obtain permission from the license holder to duplicate, adapt or reproduce the material. 